\title{
Employability themes for economic recovery
}

Helen Kofler

University of Greenwich, UK

\begin{abstract}
As part of the University of Greenwich SHIFT 2021 conference on teaching and learning, I led a discussion workshop called 'Employability themes for economic recovery' in which delegates considered economic recovery after the COVID-19 pandemic, the inevitable changes in working practices and, consequently, the changes' influence upon student employability skills development. In this article, I reflect both on the current context of significant workplace change across the globe and how we as educators should respond if we are to skill students for this new working world.
\end{abstract}

\section{A reflection}

In recent times, and especially as a result of the COVID-19 pandemic, a landmark transition from face-to-face to virtual working practices has taken place. This article explores how these changes have consequences for the technical and soft skills at work, the impact of which may be viewed through three different lenses: of the employer, the employee and the educators. Impact is also explored from a short, medium and long-term perspective. The first focus is on how economic recovery from the pandemic crisis might take shape. Next, some of the current technical advances and implications for digital literacy is reviewed. Then, having explored the evolution of the workplace, conclusions are drawn with ideas shared at the workshop which led to actions for enhancing employability skills training for students at universities.

Today, a ' $\mathrm{K}$ '-shaped recovery, in which some organisations are benefiting massively from the crisis and others are falling behind (Aldrich, E., 2020), is beginning to happen. One such example is Zoom Video Communications Inc. which, at the time of writing, is currently valued at $\$ 100$ billion in market capitalisation - roughly five times the value of British Telecom (Google Finance, 2021). One obvious reason for the success of firms like Zoom is their ability to pivot quickly and adapt to new virtual norms. Before the crisis, technology companies were one of the only sectors to have fully embraced remote working and as a result have been able to scale and ramp up services showing flexibility (Bick et al, 2020).

During the SHIFT 2021 conference workshop, delegates were asked to think conceptually about reliance on technology and reflections were made on the delegates' experiences over the last year, including engaging with colleagues and employers remotely and increasing reliance on tech (Preen, 2020). A poll was used to assess delegate response to the following statement: "The more we rely on technology the less we depend on our own intuition and judgement." The majority of delegates found this statement to be false, suggesting that most are enjoying this supplementary addition to working practice.

Virtual working has seen a rise in various trends, including: 1) a decentralised workforce which may be called 'global villages'; 2) the rise of the digital nomad; 3) growth in the 
numbers of project-based teams; 4) predictions of more flexible work, with companies hiring more freelance workers and a rise in the number of self-employed. Further, for some, remote working is fulfilling the promise of an improved work/life balance. It is clear that all of these trends will have an impact on what skills and work will be required by businesses (Global Solutions Summit, 2020).

The change to remote working will certainly alter the traditional structures of leadership and management: it has been suggested that managers can no longer operate by means of command and control (The Executive Centre, 2019). Employees now have different expectations of managers who are increasingly acting as mentors, relying on emotional intelligence and empathy in the absence of those physical cues they would have had in the office (Rowell, 2019). At the other end of the spectrum, some organisations are using software to monitor remote-working productivity, viewing remote working as a risk to output (Global Solutions Summit, 2020).

At the SHIFT 2021 conference workshop, delegates were asked to think conceptually about how they had engaged with colleagues remotely; they were also asked to respond to the statement 'Being physically close to someone is important for truly collaborative work.' Most favoured either 'partly true' or 'true' which suggests that people are missing the social interactions that come with working physically near to someone. Interestingly, some theorists suggest that relationships are formed through body language, heat and olfactory experiences; this being the case, virtual relationships are therefore lacking these dimensions of interaction (Bryan, 2020).

At the Financial Times 'New World of Work' digital dialogue event, it was suggested that companies will need to reconsider the purpose of the office, to make it functional post pandemic. During the SHIFT workshop, participants discussed whether, post pandemic, the office should be seen as a collaborative creative space and, if so, how would the design be adjusted accordingly? If architecture is relevant, how might it be configured to optimise faceto-face connections while keeping us safe? Some have suggested that, in the future, dual working - with a mixture of face-to-face and remote working according to the needs of the business - will be the norm (Financial Times Digital Dialogues, 2020).

The delegates then looked at automation and how it could affect the skills required for work. McKinsey, the management consulting company, reports that $30 \%$ of work activities could be automated by 2030, which equates to 375 million global roles (Bick et al, 2020). An increase in automation may mean we need to update our digital literacy skills but also enhance softer human skills, enabling us to thrive in these virtual conditions. Reading and filtering out short messages via connectivity software could become the new listening in virtual conditions (Clark, 2020)? There could be a need for more creativity in the content we provide to compel us into engaging, since virtual communication may not be as rewarding? How will we cope with problem-solving in times of crisis when our colleagues are not sitting next to us?

Delegates cited examples of how employers are viewing this skills gap. McKinsey says that while $87 \%$ of organisations are seeing skills gaps, only $28 \%$ are trying to close them (McKinsey Global Survey). JP Morgan has invested \$350 million dollars to develop growing technical skills and Amazon has promised $\$ 700$ million dollars to retrain employees for 
skilled roles in tech (Bick et al, 2020). Another great example is Microsoft's 'Get On 2021' which is a five-year campaign to help 1.5 million people in the United Kingdom (UK) to build careers in technology by 2025 (Financial Times Digital Dialogues, 2020).

There are lots of other examples of organisations that are adapting to help equip students and graduates with employability skills. For example, PricewaterhouseCoopers has created a virtual park to give an insight into its work setting (PwC Careers, Virtual Park, 2020). It has also created an 'Employability Hub', which delivers skills workshops and insights to support staff (PwC Careers, Employability Hub, 2020). There has also been a rise in EdTech through organisations such as Handshake, a graduate events and recruitment platform, which works with employers and universities to help make students more employable (Handshake, 2021).

To add to the discussion, recent graduates from the University of Greenwich attended the SHIFT workshop and shared their insights into the skills gaps they experienced when transitioning from higher education to remote working. Themes included: more demanding technical skills needed for specific job functions; confidence in adapting to different connectivity software platforms; resilience to use resources with little practical guidelines from others in close proximity; mental health and ways to keep yourself well when working on your own; virtual networking (a key issue) and the need for prior preparation (there are no physical cues as could have been relied upon in the physical office); general communication skills (including being able to talk openly with others about your skills and successes as they are not so readily visible in a virtual context).

Delegates reflected on a framework - from the European Skills/Competencies, qualifications and Occupations commission (ESCO) - called 'The Covid-19 Skills watcher' (European Commission, 2020). This tool combines up-to-date labour market intelligence with evolving skills in the light of the pandemic. Although this is not a formula, it will help exploration into which skills are needed for a particular role. For universities, how can these skills be built into a professional development plan or teaching schedule? This also gives educators some structure to be able to talk about skills with relevant labour market intelligence so that students can target growing industries. Educators will, therefore, not be reacting, but planning and preparing more formally via provisions of support at universities.

To conclude, the SHIFT conference workshop provided insights and provoked thought on the evolving, pandemic-related employability themes and demonstrated that more discussion is required in this area. There has clearly been a huge change to working practices and this has inevitably affected the skills graduates need for long-term success. Universities have a moral responsibility to make students more employable and so, ending the workshop with the words of Educational Reformer John Dewey, "If we teach today's students as we taught yesterday's, we rob them of tomorrow", I asked delegates to think more deeply about the topic and to set the tone for a potential future discussion on student-centric skills development (Preen, 2020). 


\section{Reference list}

Aldrich, E. (2020) 'What a K-shaped recovery means, and how it highlights a nation's economic inequalities.' Business Insider. Available at: https://www.businessinsider.com/kshaped-recoverydefinition? $r=U S \& I R=T \#: \sim: t e x t=A \% 20 K \% 2 D$ shaped\%20recovery\%20is\%20a\%20post\%2Drec ession $\% 20$ scenario\%20in,K\%22\%20\%E2\%80\%94\%20hence\%20the\%20name (Accessed: 21 February 2021).

Bick, R., Hazan, E., Khan, H., Lacroix, S., Sarrazin, H. and Welchman, T. (2020) 'The future of work: Reskilling and remote working to recover in the next normal.' McKinsey Digital, Available at: https://www.mckinsey.com/business-functions/mckinsey-digital/our-insights/thefuture-of-work-reskilling-and-remote-working-to-recover-in-the-next-normal\# (Accessed: 21 February 2021).

Bryan, A. (2020) 'Navigating the new rules of personal space in the workplace - Ideas, Wework.' Available at: https://www.wework.com/ideas/worklife/navigating-the-new-rules-ofpersonal-space-in-the-workplace (Accessed: 21 February 2021).

Clark, D. (2020) 'What your Zoom body language says about you.' Newsweek. Available at: https://www-newsweek-com.cdn.ampproject.org/c/s/www.newsweek.com/what-your-zoombody-language-says-about-you-1548438?amp=1 (Accessed: 21 February 2021).

ESCO (European Commission) (2020) Covid-19 Skills Watcher. Available at: https://ec.europa.eu/esco/portal/howtouse/bfe2a816-f9dd-49df-a7d2-ec8fafcfce95 (Accessed: 13 January 2021).

Financial Times Digital Dialogues (2020) 'The New World of Work.' Financial Times. Available at: https://newworldwork.live.ft.com/page/1649858/full-overview (Accessed: 21 February 2021).

Global Solutions Initiative - Global Solutions Summit panel discussion (2020) 'The future of work in the post pandemic world - Global Solutions Initiative.' Global Solutions Summit, Available at: https://www.global-solutions-initiative.org/global-table/the-future-of-work-in-thepost-pandemic-world/ (Accessed: 21 February 2021).

Google Finance (2021) Zoom Video Communications Inc. Google. Available at: https://www.google.com/finance/quote/ZM:NASDAQ (Accessed: 13 January 2021).

Handshake (2021) Handshake. Available at: https://www.joinhandshake.com/ (Accessed: 21 February 2021).

Preen, M. (2020) The Future of Work Guide. Available at: https://nationalcareersweek.com/2021fow/ (Accessed: 21 February 2021).

PWC Careers (2020) Employability Hub, PWC. Available at: https://www.pwc.co.uk/careers/student-careers/employabilityhub.htm|\#: :text=At\%20PwC\%2C\%20we're\%20focussed,Explore\%20our\%20different\%20re sources\%20below (Accessed: 21 February 2021). 
PWC Careers (2020) Virtual Park, PWC. Available at:

https://www.pwc.co.uk/careers/student-careers/undergraduate-graduate-

careers/ourevents/virtual-park.html (Accessed 21 February 2021).

Rowell, C. (2019) 'Here's why trust is key when embracing a flexible workplace.' Wework. Available at: https://www.wework.com/ideas/office-design-space/heres-why-trust-is-keywhen-embracing-a-flexible-workplace (Accessed: 21 February 2021).

The Executive Centre (2019) 'Open Plan Design: What Have We Learned?' The Executive Centre. Available at: https://www.executivecentre.com/blog-article/open-plan-design-whathave-we-learned/ (Accessed: 21 February 2021). 